\title{
Prevalence of Suspected Cases of Hyperthyroidism in Jeddah by Using Wayne's Scoring Index
}

\author{
Mohammed Qashqary ${ }^{1,2}$, Mansour Tobaiqy ${ }^{3}$, Manal M. Al-Sutari ${ }^{4}$, Alaa Mujallad ${ }^{4}$, Intisar Alsheikh ${ }^{4}$

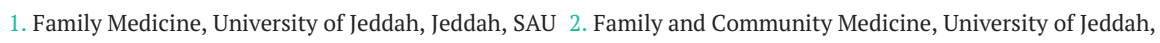 \\ Jeddah, SAU 3. Pharmacology, College of Medicine, University of Jeddah, Jeddah, SAU 4. Nursing, University of Jeddah, \\ Jeddah, SAU
}

Corresponding author: Mohammed Qashqary, meqashqary@uj.edu.sa

\section{Abstract}

\section{Introduction}

Hyperthyroidism is one of the primary dysfunctional thyroid diseases that results from abnormally high thyroid hormone secretion. It leads to metabolic derangement that manifests as heightened vital functions and metabolism and hyperdynamic blood circulation. Hyperthyroidism jeopardizes one's quality of life and hampers the patient's job performance. The disease is chronic but diagnosable and treatable and can be kept under control medically. We aimed to estimate the prevalence of suspected hyperthyroidism cases among a population sample in Jeddah city by using Wayne's scoring and delineation of factors associated with the disease.

\section{Materials and methods}

A cross-sectional study design was used. A total of 346 participants were conveniently selected from two shopping malls in Jeddah city during a five-day health awareness campaign. The data were collected by certified physicians, according to Wayne's score inventory.

\section{Results}

The study included 194 women (56.1\%) and 152 men (43.9\%). The participants' ages ranged from 16 to 56 years. The Wayne's scores showed $80.6 \%$ were euthyroid, $18.2 \%$ equivocal, and $1.2 \%$ have hyperthyroidism. Bronchial asthma was significantly associated with hyperthyroidism in men, while obesity was significantly associated with hyperthyroidism in women. Age, gender, level of education, and family history of chronic diseases, including thyroid disorders, were not significantly associated with hyperthyroidism.

\section{Conclusions}

Wayne's scoring for hyperthyroidism, which is a noninvasive tool, in addition to its detection of

Review began 10/12/2020 Review ended 11/15/2020 Published 11/17/2020

\section{(c) Copyright 2020}

Qashqary et al. This is an open access article distributed under the terms of the Creative Commons Attribution License CC-BY 4.0., which permits unrestricted use, distribution, and reproduction in any medium, provided the original author and source are credited. hyperthyroidism cases, can predict patients with equivocal results or those that might be subclinical for further medical assessment and follow-up. A Wayne's score can give the results of hyperthyroidism comparable to the results obtained by biochemical investigations. This tool is not in common use, but it is quite useful and should be put into broader usage.

Categories: Endocrinology/Diabetes/Metabolism, Family/General Practice, Public Health

Keywords: key words: hyperthyroidism, jeddah, wayne's index

\section{Introduction}

Since the discovery of oil in Saudi Arabia, which positively affected its socioeconomic status, notable improvements have been seen across many sectors of the country. Healthcare is one of the sectors that has undergone remarkable advancements. The government has allocated large amounts of oil revenue to develop the healthcare system in the country. The healthcare organizations in Saudi Arabia deliver highquality, up-to-date services that provide the best patient outcomes. Health awareness levels have increased in Saudi Arabian society due to the beneficial progress in the healthcare system [1]. Early discovery and prevention of diseases such as endocrine disorders are essential to reduce both prevalence and associated costs. Thyroid diseases are common endocrine disorders in Saudi Arabia and the rest of the Middle East but are usually misunderstood or misdiagnosed [2].

Hyperthyroidism is one of the endocrine disorders that occurs due to excessive production of the thyroid hormones, which are triiodothyronine and thyroxine, and characterized by low serum thyroid-stimulating hormone. Physical examination remains paramount to detect hyperthyroidism if a blood test is not available. Wayne's index score is a clinical tool used to establish a clinical diagnosis for hyperthyroidism [3]. 
Hyperthyroidism is a hypermetabolic disorder that is difficult to diagnose because the symptoms can mimic many other diseases and could lead to an inaccurate diagnosis and mismanagement. If untreated, this can lead to significant mortality [4]. The exact cause of hyperthyroidism is not reliably defined; however, the most common cause of thyroid disorders is iodine deficiency [5]. Hyperthyroidism's common symptoms are nervousness, intolerance of heat, weight loss despite appetite increase, and the body becoming warm and wet [6]. The main hyperthyroidism disorders are Graves' disease, thyroid storm, toxic thyroid nodule, toxic nodular struma, and hashitoxicosis [2].

As the healthcare system leans toward limiting the use of many diagnostic tests, Wayne's index has been useful in diagnosing hyperthyroidism. According to Naraintran et al., Sir Edward Wayne had implemented the index to find a primary result through a quantification score that will provide physicians with results to perform a referral [3]. Wayne's index is a clinical diagnostic tool to enhance the accuracy of hyperthyroidism assessments. The score will be divided into three parts: the people who will get a score above 19 are considered to have toxic hyperthyroidism, a score from 11 to 19 is equivocal, and less than 11 is considered euthyroidism [7]. The present study aims to estimate the prevalence of suspected hyperthyroidism cases by using Wayne's index score and the factors that increase the risk of suspected cases of hyperthyroidism.

\section{Materials And Methods}

The study was a cross-sectional analytic study performed in Jeddah (Kingdom of Saudi Arabia), conducted in October 2019 for five days during an awareness campaign organized by the College of Applied Medical Sciences of Jeddah University for the public in two shopping malls in Jeddah, Saudi Arabia. The campaign was held in the Red Sea and the Arab malls from 17 to 19 of October and 24 to 25 of October, respectively.

The inclusion criterion was for the participant to be older than age 16. Participants who had a history of any thyroid disorders were excluded from the study.

The study was conducted using a self-administered Arabic questionnaire. An endocrinology consultant validated the questionnaire. It consists of three parts to assess the prevalence of suspected hyperthyroidism cases in Jeddah by using Wayne's scoring index. The first part was composed of questions regarding demographic data, the second part consisted of questions about thyroid disease symptoms, and the third part was related to thyroid gland examination.

The data were collected by physicians working in the medical centers of Jeddah University. They received training by one of the study investigators on each section of the questionnaire. Informed consent was obtained from the participants. Physicians sat with the participants and supervised them when they were filling out the first part of the questionnaire. Then, they asked the participants questions about the symptoms of thyroid diseases, according to Wayne's index. After that, they obtained permission from the participants to do the thyroid examination according to Wayne's index. The examination was done in private places, especially for women. Then, the scores of the participants were calculated. When the participants' scores were equal or more than 11 , physicians informed them that they had a risk of developing hyperthyroidism and advised them to go to the nearest primary healthcare center to have laboratory tests for hyperthyroidism confirmation and follow-up.

The sample size was calculated using OpenEpi, assuming the total targeted population is 3,000,000 individuals, and based on a previous study on the Saudi population that concluded the prevalence of hyperthyroidism was $2.8 \%$ [8]. The calculated sample size required was 346 individuals at an approximately 93.5\% confidence limit.

The Research Ethics Committee approved this study at the College of Applied Medical Sciences of Jeddah University. Physicians informed all participants that all information would be kept confidential and will not be accessed except for scientific research.

IBM SPSS Statistics for Windows, Version 20.0. (IBM Corp., Armonk, NY) was used for data entry and analysis. The records were double-checked and entered by two researchers. Data were then analyzed using descriptive statistics. A Chi-square test was performed to identify the odds ratio, relative risk, positive predictive value, and negative predictive value between variables such as family history, chronic disease with the thyroid disease at a significance level of 0.05 .

\section{Results}

A total of 346 participants took part in the study. The age of the participants ranged from 16 to 56 years. The mean age of the participants was 32 years $(S D=9.6)$. More than half of the participants $(n=194,56.1 \%)$ were women (152 men; 43.9\%) and had a bachelor's degree $(n=175,50.6 \%$; Table 1$)$, and $75.7 \%(n=262)$ have a family medical history free of thyroid disorders (Table 2 ). 


\section{Cureus}

\begin{tabular}{|c|c|c|c|}
\hline & & Frequency & Percent \\
\hline \multirow{5}{*}{ Age } & $16-25$ years & 81 & $23.4 \%$ \\
\hline & $26-35$ years & 102 & $29.5 \%$ \\
\hline & $36-45$ years & 77 & $22.3 \%$ \\
\hline & $46-55$ years & 60 & $17.3 \%$ \\
\hline & More than 56 years & 26 & $7.5 \%$ \\
\hline \multirow{2}{*}{ Gender } & Men & 152 & $43.9 \%$ \\
\hline & Women & 194 & $56.13 \%$ \\
\hline \multirow{7}{*}{ Education } & Primary & 7 & $2.0 \%$ \\
\hline & Intermediate & 12 & $3.5 \%$ \\
\hline & High school & 91 & $26.3 \%$ \\
\hline & Post & 31 & $9.0 \%$ \\
\hline & Diploma & 24 & $6.9 \%$ \\
\hline & Bachelor & 175 & $50.6 \%$ \\
\hline & Uneducated & 6 & $1.7 \%$ \\
\hline
\end{tabular}

TABLE 1: Distribution of sample study according to their sociodemographic data

\begin{tabular}{|c|c|c|c|}
\hline \multicolumn{2}{|c|}{ Have you ever been diagnosed a family member with thyroid diseases? } & Frequency & Percent \\
\hline \multicolumn{2}{|l|}{ Yes } & 84 & $24.3 \%$ \\
\hline \multicolumn{2}{|l|}{ No } & 262 & $75.7 \%$ \\
\hline \multicolumn{2}{|l|}{ Total } & 346 & $100.0 \%$ \\
\hline \multicolumn{4}{|c|}{$\begin{array}{l}\text { According to Wayne's scoring, more than two-thirds of the participants }(\mathrm{n}=279,80.6 \%) \text { were euthyroid, } \\
18.2 \%(\mathrm{n}=63) \text { were equivocal, and only } 1.2 \% \text { of the participants }(\mathrm{n}=4) \text { showed signs of hyperthyroidism } \\
\text { (Table 3). }\end{array}$} \\
\hline \multicolumn{2}{|l|}{ Thyroid function } & \multicolumn{2}{|l|}{ Percent } \\
\hline \multicolumn{2}{|l|}{ Euthyroid } & \multicolumn{2}{|l|}{$80.6 \%$} \\
\hline \multicolumn{2}{|l|}{ Equivocal } & \multicolumn{2}{|l|}{$18.2 \%$} \\
\hline \multicolumn{2}{|l|}{ Hyperthyroid } & \multicolumn{2}{|l|}{$1.2 \%$} \\
\hline \multicolumn{2}{|l|}{ Total } & \multicolumn{2}{|l|}{$100.0 \%$} \\
\hline
\end{tabular}

TABLE 3: Distribution of the study sample according to Wayne's scoring

The Chi-square test was used to test the association between Wayne's scores and the participants' sociodemographic characteristics. The results demonstrated that age, gender, level of education, and family history of chronic diseases, including thyroid disorders, were not significantly associated with hyperthyroidism (Tables 4-6). 


\section{Cureus}

\begin{tabular}{|c|c|c|c|c|}
\hline \multirow{2}{*}{ Age } & & \multicolumn{2}{|c|}{ Wayne's score } & \multirow{2}{*}{ P-value } \\
\hline & & Negative & Positive & \\
\hline \multirow{2}{*}{$16-25$ Years } & Count & 67 & 14 & \multirow{10}{*}{0.142} \\
\hline & $\%$ Within age & $82.7 \%$ & $17.3 \%$ & \\
\hline \multirow{2}{*}{$26-35$ Years } & Count & 75 & 27 & \\
\hline & $\%$ Within age & $73.5 \%$ & $26.5 \%$ & \\
\hline \multirow{2}{*}{36 - 45 Years } & Count & 62 & 15 & \\
\hline & \% Within age & $80.5 \%$ & $19.5 \%$ & \\
\hline \multirow{2}{*}{46 - 55 Years } & Count & 54 & 6 & \\
\hline & \% Within age & $90.0 \%$ & $10.0 \%$ & \\
\hline \multirow{2}{*}{ More than 56 Years } & Count & 21 & 5 & \\
\hline & \% Withhin age & $80.8 \%$ & $19.2 \%$ & \\
\hline
\end{tabular}

TABLE 4: Association of Wayne's score with age

\begin{tabular}{|c|c|c|c|c|}
\hline \multirow{2}{*}{ Gender } & & \multicolumn{2}{|c|}{ Wayne's score } & \multirow{2}{*}{ P-value } \\
\hline & & Negative & Positive & \\
\hline \multirow{2}{*}{ Men } & Count & 123 & 29 & \multirow{4}{*}{0.905} \\
\hline & $\%$ Within gender & $80.9 \%$ & $19.1 \%$ & \\
\hline \multirow{2}{*}{ Women } & Count & 156 & 38 & \\
\hline & $\%$ Within gender & $80.4 \%$ & $19.6 \%$ & \\
\hline
\end{tabular}




\section{Cureus}

\begin{tabular}{|c|c|c|c|c|}
\hline \multirow{2}{*}{ Education } & & \multicolumn{2}{|c|}{ Wayne's score } & \multirow{2}{*}{ P-value } \\
\hline & & Negative & Positive & \\
\hline \multirow{2}{*}{ Primary } & Count & 5 & 2 & \\
\hline & \% Within education & $71.4 \%$ & $28.6 \%$ & \\
\hline \multirow{2}{*}{ Intermediate } & Count & 10 & 2 & \\
\hline & $\%$ Within education & $83.3 \%$ & $16.7 \%$ & \\
\hline \multirow{2}{*}{ High school } & Count & 68 & 23 & \\
\hline & $\%$ Within education & $74.7 \%$ & $25.3 \%$ & \\
\hline \multirow{2}{*}{ Post } & Count & 25 & 6 & 0.599 \\
\hline & $\%$ Within education & $80.6 \%$ & $19.4 \%$ & \\
\hline \multirow{2}{*}{ Diploma } & Count & 20 & 4 & \\
\hline & $\%$ Within education & $83.3 \%$ & $16.7 \%$ & \\
\hline \multirow{2}{*}{ Bachelor } & Count & 145 & 30 & \\
\hline & $\%$ Within education & $82.9 \%$ & $17.1 \%$ & \\
\hline Uneducated & Count & 6 & 0 & \\
\hline
\end{tabular}

TABLE 6: Association of Wayne's score with the level of education

A Chi-square test was used to detect the association between Wayne's scores and gender and chronic diseases (Table 7). The results showed that a history of having bronchial asthma was significantly associated with hyperthyroidism in men, while obesity was significantly associated with hyperthyroidism in women. However, Wayne's scores were not significantly associated with gender, among other chronic diseases. 


\section{Cureus}

\begin{tabular}{|c|c|c|c|c|c|}
\hline \multirow{2}{*}{$\begin{array}{l}\text { Gender } \\
\text { Wayne's score }\end{array}$} & & \multicolumn{2}{|l|}{ Male } & \multicolumn{2}{|l|}{ Female } \\
\hline & & Negative & Positive & Negative & Positive \\
\hline \multirow{2}{*}{ Thyroid disorder } & No & 122 & 29 & 152 & 38 \\
\hline & Yes & 1 & 0 & 4 & 0 \\
\hline P-value & & 0.626 & & 0.319 & \\
\hline \multirow{2}{*}{ Diabetic } & No & 109 & 28 & 144 & 34 \\
\hline & Yes & 14 & 1 & 12 & 4 \\
\hline P-value & & 0.198 & & 0.569 & \\
\hline \multirow{2}{*}{ Blood pressure } & No & 111 & 27 & 143 & 35 \\
\hline & Yes & 12 & 2 & 13 & 3 \\
\hline P-value & & 0.632 & & 0.930 & \\
\hline \multirow{2}{*}{ Obesity } & No & 115 & 28 & 154 & 35 \\
\hline & Yes & 8 & 1 & 2 & 3 \\
\hline P-value & & 0.531 & & 0.021 & \\
\hline \multirow{2}{*}{ Heart disease } & No & 119 & 28 & 153 & 38 \\
\hline & Yes & 4 & 1 & 3 & 0 \\
\hline P-value & & 0.957 & & 0.389 & \\
\hline \multirow{2}{*}{ Asthma } & No & 123 & 28 & 154 & 38 \\
\hline & Yes & 0 & 1 & 2 & 0 \\
\hline P-value & & 0.039 & & 0.483 & \\
\hline
\end{tabular}

TABLE 7: Association of Wayne's score with gender and chronic diseases

\section{Discussion}

According to the published medical records and to the best of our knowledge, this study is the first to address hyperthyroidism using Wayne's score as a tool of assessment in the Kingdom of Saudi Arabia and other Arab countries. However, the published reports in the Kingdom used biochemical and other clinical methods $[9,10]$. Therefore, this study's findings were compared to findings derived from biochemical testing due to the lack of reports of Wayne's score. One study in India evaluated Wayne's score and concluded that it had $86.9 \%$ sensitivity and $96 \%$ specificity [3]. Another study from Nigeria compared Wayne's scoring of participants to their biochemical testing of thyroid hormones, and they found a similar outcome [11]. Wayne's score has high reliability, is easy, and a noninvasive tool for assessing hyperthyroidism, but unfortunately, it is rarely used. In this study, we found that $1.2 \%$ of the study sample conformed to the criteria of positive Wayne's score, which means they have hyperthyroidism. This finding is consistent with the prevalence rate of hyperthyroidism reported in other studies. As an example, Hasanato et al. reported a $3 \%$ incidence of hyperthyroidism among women attending a hospital in Riyadh according to their collected history [12]. A study in Jordan reported the prevalence of hyperthyroidism as $1.8 \%$ in women and $2.27 \%$ in men [13]. A study from Sudan reported a prevalence of 3.4\% of hyperthyroidism among pregnant women attending antenatal clinic in a hospital [14]. These reports, including our findings, were consistent with hyperthyroidism's global prevalence, ranging from $0.2 \%$ to $1.3 \%$ [15]. The consistency of hyperthyroidism's biochemical diagnosis with Wayne's score supports its reliability as a practical noninvasive tool for diagnosing hyperthyroidism. According to Wayne's score in this study, $18.2 \%$ of the participants were equivocal scores for hyperthyroidism. This finding cannot be ignored because those participants might be on the verge of hyperthyroidism or in a state of sub-clinical hyperthyroidism. This equivocal group needs further assessment and follow-up because they may develop overt hyperthyroidism in the future.

The association of age and gender in this study was insignificant for hyperthyroidism $(\mathrm{P}=0.142)$. This finding was contradicted by other reports that linked hyperthyroidism significantly with increased age and female gender $[16,17]$. This could be attributed to the use of different methods for testing for hyperthyroidism. This study showed no significant difference between men and women in their scoring 
regarding hyperthyroidism. This finding did not agree with a common medical practice that thyroid dysfunctions, including hyperthyroidism, are more common in women. The most typical cause of hyperthyroidism is Graves' disease, and autoimmune diseases are more common in women and therefore, hyperthyroidism is more common in them; this is generally accepted $[12,16,17]$. We found that education did not significantly differ in hyperthyroidism levels, which may reflect similar awareness among people of different educational levels. A study in Saudi Arabia reported that 57.32\% of the sample lacked knowledge, and the rest had poor information about thyroid gland disorders [18]. In that report, age, gender, education level, and occupation had no significant effect on the degree of awareness about thyroid diseases. These findings were consistent with the outcome of this study [18].

Our study did not find a significant association between hyperthyroidism and history of thyroid disorders, diabetes mellitus, hypertension, and heart diseases. Bronchial asthma was found to be correlated with hyperthyroidism in men. Different studies reported similar findings, and hyperthyroidism reduces the chance of remission of bronchial asthma among men $[19,20]$. Obesity among women was found to be a significant factor for hyperthyroidism, according to this study. In the medical literature and clinical practice, hyperthyroidism is associated with weight loss due to a high basal metabolic rate that requires increased energy consumption. However, the patient's appetite with hyperthyroid is increased, and sometimes the balance might be tipped toward weight gain due to excessive food intake. Such a finding was reported by Saeed et al. in a study from Iraq's northern region [21]. This indicates that obese people are also prone to develop hyperthyroidism; this is a fact that warrants notice by medical personnel. Moreover, the treatment of patients with hyperthyroidism can be followed by significant weight gain and even obesity, as reported $[22,23]$.

\section{Conclusions}

Wayne's score is not in common use, but it is quite useful and should be put into broader usage. In our study, the prevalence of suspected hyperthyroidism cases in Jeddah city by using Wayne's scoring was quite common.

Further studies require the measurement of thyroid function tests of the suspected cases and to evaluate the association between bronchial asthma and obesity with hyperthyroidism in men and women respectively.

\section{Additional Information}

\section{Disclosures}

Human subjects: All authors have confirmed that this study did not involve human participants or tissue. Animal subjects: All authors have confirmed that this study did not involve animal subjects or tissue. Conflicts of interest: In compliance with the ICMJE uniform disclosure form, all authors declare the following: Payment/services info: All authors have declared that no financial support was received from any organization for the submitted work. Financial relationships: All authors have declared that they have no financial relationships at present or within the previous three years with any organizations that might have an interest in the submitted work. Other relationships: All authors have declared that there are no other relationships or activities that could appear to have influenced the submitted work.

\section{References}

1. Alotaibi A: Optometry services in Saudi Arabia. Global J Health Sci. 2017, 9:91. 10.5539/gihs.v9n8p91

2. Alanazi S, Abo El-Fetoh N, Alenezi H, et al.: Pattern of thyroid diseases in Arar City, Northern Saudi Arabia . Egypt J Hosp Med. 2018, 70:1834-1841. 10.12816/0044762

3. Naraintran S, David SK, Raveendran K, Pillai B: Accuracy of Wayne's criteria in diagnosing hyperthyroidism: a prospective study in South Kerala, India. Int Surg J. 2018, 5:1267. 10.18203/2349-2902.isj20181056

4. Alrasheedi A, Alsahli M, Ibrahim I, et al.: Patterns of thyroid disorders and associated metabolic changes in Northern Saudi Arabia. Eur J Biomed Pharm Sci. 2016, 7:11.

5. Leung AM, Braverman LE: Consequences of excess iodine. Nat Rev Endocrinol. 2014, 10:136-142. 10.1038/nrendo.2013.251

6. Razi A, Golforoushan F, Nejad AB, Goldust M: Evaluating of dermal symptoms in hypothyroidism and hyperthyroidism. Pak J Biol Sci. 2013, 16:541-544. 10.3923/pjbs.2013.541.544

7. Ale AO, Odusan OO, Afe TO, Adeyemo OL, Ogbera AO: Bone fractures among adult Nigerians with hyperthyroidism: risk factors, pattern and frequency. J Endocrinol Diabetes Metab South Afr. 2019, 24:28-31. 10.1080/16089677.2018.1541669

8. Gaffer Ali AA, Altahir SA: Prevalence of thyroids dysfunction among Saudi adult males and females from (June-September 2016). J Endocrinol Diab. 2016, 3:1-3. 10.15226/2374-6890/3/4/00159

9. Jammah AA, Alshehri AS, Alrakhis AA, et al.: Characterization of thyroid function and antithyroid antibody tests among Saudis. Saudi Med J. 2015, 36:692-697. doi:10.15537/ smj.2015.6.11591

10. Abbas M, Tayrab E, Elmakki A, Tayrab J, Al-Shahrani A, Miskeen E, Salih K: Primary thyroid stimulating hormone screening for congenital hypothyroidism in King Abdullah Hospital, Bisha, Saudi Arabia. Cureus. 2020, 12:e7166. 10.7759/cureus.7166

11. Sabir AA, Iwuala SO, Fasanmade OA, Abubakar SA, Haruna GY, Chowvoriole AE: Correlation between Wayne's score and laboratory evidence of thyrotoxicosis in Nigeria. Sub-Saharan Afr J Med. 2014, 1:142-144. $10.4103 / 2384-5147.138944$ 
12. Hasanato R, Mirah JA, Al-Shahrani N, Alfulayyih N, Almutairi A, Ogailan B, Fatma S: Incidence of thyroid diseases in female Saudi adults visiting a tertiary care hospital in Riyadh. Epidemiology (Sunnyvale). 2017, 7:286. 10.4172/2161-1165.1000286

13. Abu-Helalah M, Alshraideh HA, Al-Sarayreh SA, Al Shawabkeh AH, Nesheiwat A, Younes N, Al-Hader A: A cross-section study to assess the prevalence of adult thyroid dysfunction disorders in Jordan. Thyroid. 2019, 29:1052-1059. 10.1089/thy.2018.0579

14. Saeed AK, Yasin K, Elmahdi EM, Maralyn D, Ali AA: The prevalence of thyroid dysfunction among Sudanese pregnant women. SOJ Gynecol, Obstet Women Health. 2015, 1:5. 10.15226/2381-2915/1/1/00103

15. Taylor PN, Albrecht D, Scholz A, Gutierrez-Buey G, Lazarus JH, Dayan CM, Okosieme OE: Global epidemiology of hyperthyroidism and hypothyroidism. Nat Rev Endocrinol. 2018, 14:301-316. 10.1038/nrendo.201818

16. De Leo S, Lee SY, Braverman LE: Hyperthyroidism. Lancet. 2016, 388:906-918. 10.1016/S01406736(16)00278-6

17. Meng Z, Liu M, Zhang Q, et al.: Gender and age impacts on the association between thyroid function and metabolic syndrome in Chinese. Medicine (Baltimore). 2015, 94:e2193. 10.1097/MD.0000000000002193

18. Almuzaini A, Alshareef B, Alghamdi S, et al.: Assessment of knowledge and awareness regarding thyroid disorders among Saudi people. IJDMC. 2019, 3:1070-1076. 10.24911/JMDC.511568037206

19. Bingyan Z, Dong W: Impact of thyroid hormones on asthma in older adults . J Int Med Res. 2019, 47:41144125. 10.1177/0300060519856465

20. Kamaeva I, Shaporova N: The possible mechanisms of worsening bronchial asthma coexisting with thyroid gland pathology. Eur Respir J. 2014, 42:P585.

21. Saeed R, Haurami T, Mhwee T: Association of hyperthyroidism and obesity. FASEB J. 2012, 26:818.11. 101096/fasebj. 26.1_supplement.818.11

22. Torlinska B, Nichols L, Mohammed MA, McCabe C, Boelaert K: Patients treated for hyperthyroidism are at increased risk of becoming obese: finding from a large prospective secondary care cohort. Thyroid. 2019, 29:1380-1389. 10.1089/thy.2018.0731

23. Laurberg P, Knudsen N, Andersen S, Carlé A, Pedersen IB, Karmisholt J: Thyroid function and obesity. Eur Thyroid J. 2012, 1:159-167. 10.1159/000342994 